\title{
Determinants of Long-Term Unemployment in Brazil in 2013
}

\author{
Elano F. Arruda ${ }^{1}$, Daniel B. Guimarães ${ }^{2}$, Ivan Castelar $^{3} \&$ Pablo U. C. Castelar ${ }^{4}$ \\ ${ }^{1}$ Department of Applied Economics (DEA/MAER/CAEN/UFC), Fortaleza, Brazil \\ ${ }^{2}$ Department of Business (DA/UFC), Fortaleza, Brazil \\ ${ }^{3}$ Department of Finance (CAEN/UFC), Fortaleza, Brazil \\ ${ }^{4}$ Department of Finance (UFC), Fortaleza, Brazil \\ Correspondence: Elano F. Arruda, Avenida da Universidade, 2700 - 2 Floor. Zip code: 60020-181. Benfica - \\ Fortaleza/CE, Brazil. Tel: 85-3366-7751. E-mail: elano@ufc.br
}

Received: March 20, 2018

Accepted: April 21, 2018

Online Published: April 30, 2018

doi:10.5539/ijef.v10n6p53

URL: https://doi.org/10.5539/ijef.v10n6p53

\begin{abstract}
This work analyzes the determinants of the probability of a Brazilian worker being unemployed for more than a year, using data from the 2013 National Household Survey (PNAD) and applying a probit model. The results show a lower chance of remaining jobless of males, heads of households, those who declared themselves black, younger people, those who completed higher education or are in the process of acquiring it, and residents of the Southeast and South regions of Brazil. The probabilistic scenarios show that the Brazilian workers least likely to remain unemployed for over a year are males, residents in the South or Southeast region, heads of a household, between 36 and 45 years of age, with higher education, with only a $0.6 \%$ chance of remaining in that condition. On the other hand, the workers with the highest chance of remaining unemployed are females, between 46 and 65 years old, residents in the North region, illiterate and not household heads, with a $41 \%$ probability of remaining unemployed.
\end{abstract}

Keywords: long-term unemployment, probit, Brazil

\section{Introduction}

The changes in the Brazilian economy starting in the 1990s, resulting from the productive restructuring, economic liberalization and fiscal adjustments which occurred during that time, caused structural shifts in the country's economic organization (Note 1). As a result of this process, one can observe a new configuration of the Brazilian labor market, mainly characterized by significant changes in the average time of unemployment.

This new unemployment profile has resulted in the increasing marginalization of workers in productive activities, with considerable waste of the labor force and an increase in one of the most perverse forms of social exclusion (Note 2).

The existence and duration of unemployment, besides reducing basic survival conditions, imply the loss of forms of acquaintanceship in modern society. When the persistence of unemployment is extended, this problem is aggravated for two reasons. First, it reduces the probability of re-entry into the labor market, and second it can lead the individual into precarious occupation in the informal sector, which could trigger an increase in poverty and crime (Note 3). Therefore, the analysis of the social costs of unemployment should take into account not only the distribution of unemployment among the various social groups, but also the extent and intensity to which this affects them.

Although the unemployment rate is an important indicator of economic activity, it provides an incomplete view of the operating conditions of the labor market. Ehrenberg and Smith (2008) argue that a 10\% unemployment rate, for example, may indicate at least two possibilities in the job market. On one hand, it can describe a situation in which every month, $10 \%$ of the labor force becomes unemployed for only two months. In this case, the labor market is quite dynamic, with an intense flow of job losses, but with relatively small duration. On the other hand, it may reflect that $10 \%$ of the workforce is permanently unemployed, representing a stagnant market, with distortions in the demand for labor.

Although the political concern is focused on the unemployment rate, in order to understand its determinants one should analyze how the transition of individuals from unemployment to employment works, and how their 
inherent or acquired attributes interfere in this dynamic (Ehrenberg \& Smith, 2008). It is obviously more problematic for society if small groups of individuals are unemployed for longer periods, than if many people quickly go through the unemployment state, which would then be characterized as frictional unemployment.

According to Bivar (1993), it is important to assess not only the unemployment rate, but also the length of time workers remain in such condition, i.e., the persistence of unemployment, the time that workers use to find work and the obstacles during the process of searching for a job.

Given these facts, this work aims to identify the determinants of long-term unemployment in Brazil (Note 4); i.e. what factors increase the chances of Brazilians spending more time unemployed. Additionally, due to the specificities of each region of the country, this work also examines the regional dynamics of the labor market, to identify which regions are the most dynamic, and in which of those regions individuals are more likely to remain unemployed for over a year. This information is relevant because it can support public policies to reduce long-term unemployment and regional disparities in Brazil.

To carry out this analysis, data from the National Household Survey (PNAD -Pesquisa Nacional por Amostra de Domicílios), conducted by the Brazilian Institute of Geography and Statistics (IBGE - Instituto Brasileiro de Geografia e Estatística) for the year 2013, will be used, as well as a binary regression model. It should be noted that among the works in the academic literature that have investigated the determinants of the duration of unemployment in Brazil, the vast majority of them make use of the Monthly Employment Survey (PME Pesquisa Mensal de Emprego), carried out by the IBGE. However, that survey is limited to only six metropolitan regions of Brazil, which makes it impossible to conduct an analysis of national coverage as well as an appraisal of the possible disparities between regions, which is the present intent.

Therefore, this work aims to fill this gap by analyzing the determinants of long-term unemployment considering information from all the federal units of Brazil (states and Federal District), with the possibility of identifying their regional differences. Another contribution is the analysis of probabilistic scenarios made possible by using discrete choice models, in which one can measure the likelihood that an individual with certain characteristics will remain unemployed for longer than 12 months.

Apart from this introduction, this work has five more sections. The next section features a review of the literature, covering the empirical evidence and theoretical aspects of the subject. Then a brief discussion of the data used is presented, as well as a description of the long-term unemployment profile for Brazil and its regions. In the following section, the methodological aspects are discussed. The results and analysis of marginal effects and probabilistic scenarios are discussed in the fourth section. The last section contains the concluding remarks.

\section{Literature Review}

In recent years, several works have analyzed the duration of unemployment in Brazil and other countries. In the international literature, the first academic works which sought explanations for the duration of unemployment date from the 1970s, and among those the standouts are Lancaster (1979), Nickell (1979) and Lancaster and Nickell (1980), which feature in their methodology models with risk functions in order to analyze the duration of unemployment. In the following decade, many works, such as Alogoskoufis et al. (1988) and Barro (1988), were dedicated to better understanding the persistence of unemployment.

More recent examples of academic research on unemployment are the articles of Boršič and Kavkler (2009) and Du and Dong (2008), which found that women take longer to find work than men, when analyzing Slovenia and China, respectively. Theodossiou and Zarotiadis (2010), studying Greece, observed that the duration of unemployment, when experienced previously, especially by women, people over 45 years of age and employees of the trade or service sectors, positively affects the duration of unemployment in a future period.

Schneider (2011) analyzed long-term unemployment in the context of the recent economic recession that affected various countries, particularly the US, and when focusing on that country, the author finds that across all categories, people aged from 55 to 64 years had the highest unemployment rates and the longest durations of unemployment. The less educated were shown to remain jobless longer, particularly from the age of 45 onwards. Blacks/African Americans and Asians had longer spells of unemployment than Whites across all age groups. Also, the author stated that trouble finding work for older workers was the case regardless of gender, race and ethnicity. However, men and women showed almost no differences in the duration of unemployment.

Although the duration of unemployment is a relevant variable, a quick review of academic works on the labor market in Brazil shows a certain lack of attention to this topic. The first analysis of the kind in Brazil was only made in the 1990s, by Bivar (1993), who analyzed the expected duration of unemployment occurrences in the metropolitan region of São Paulo for the period from 1983 to 1990, using data from the Monthly Employment 
Survey (PME), and found an average expected duration of six months, and that $66 \%$ of unemployed people remained in that condition for more than six months. After the pioneering work of Bivar (1993), other authors began to focus on studying the determinants of unemployment in Brazil.

Penido and Machado (2000) analyzed the duration of unemployment for the metropolitan region of Belo Horizonte, finding an average of seven months, and that individuals with higher education and who have been unemployed for a longer period are less likely to find a new job. Also studying Belo Horizonte, Antigo and Machado (2006) found that younger people and those who were unemployed for a longer period had higher incidences of remaining jobless and lower probabilities of leaving this condition.

As for São Paulo, Avelino (2001) noted that the unemployed heads of the household, males who were not going to school, those who had worked previously, and those who had no formal contract in their last job and had a previous job in the construction industry, were the ones who found jobs the fastest.

Menezes and Dedeca (2006) analyzed the complete duration of unemployment in the metropolitan areas of Salvador and São Paulo, in the period between 2000 and 2002. The authors also found that the unemployment rate influences the duration of unemployment. The results showed an average duration at the steady state of 9.4 months for the metropolitan region and of 8.8 months for the São Paulo metropolitan region.

Oliveira and Carvalho (2006) used data from the survey of standard of living (PPV - Pesquisa Sobre o Padrão de Vida) of the IBGE and found, among other results, that the educational level of workers has a negative effect on the risk of leaving the state of unemployment. Women and older workers also exhibited a negative effect, indicating some level of discrimination in Brazil's labor market.

The great majority of works have focused on metropolitan areas of Brazil. In one such work, Menezes Filho and Picchetti (2000) found that the expected duration of unemployment is greater for older individuals, those who are not the main household provider, the most educated, those who were dismissed from their last job, those with lower turnover rates, those who wish to be employed in the formal sector and those without work experience. They also found that the rate of leaving unemployment is greater between the first and the sixth month of duration. Penido and Machado (2002) found that individuals with a primary school education, who had been unemployed for a longer period, who are elderly and are female, are less likely to find a new job.

Meneses and Cunha (2012) used, in addition to the personal characteristics of unemployed individuals, macroeconomic and regional aspects. The results suggested that the probability of remaining unemployed is higher for females, more educated people, non-whites and those who are not the head of the households. In addition, they found that individuals in the metropolitan areas of Salvador and Rio de Janeiro remain unemployed longer, and this is positively correlated with unemployment and inflation levels, and negatively correlated with the average income of the worker and the gross domestic product.

To analyze how the duration of unemployment and characteristics of workers are related to the probability of transitioning from unemployment to formal employment, informal employment and remaining inactivate, Reis and Aguas (2014), using longitudinal data of the PME and econometric models that measure the duration of unemployment, showed that the probability of an unemployed worker getting a job, either formal or informal, increases with the duration of unemployment, and that the probability of transition from unemployment to inactivity also increases with the unemployment time. Also, the probabilities of transition to a formal employment are higher for the more educated, males and young people.

Aiming to analyze the validity of the current methods of distinction between unemployment and inactivity, Aguas, Pero and Ribeiro (2014) used an approach based on the behavior of a category of individuals who are not employed and do not seek work, but have the desire to work. The authors found that inactive people who want to work have clearly distinct behavior to those who do not seek and do not want to work, the latter being closer to the state of unemployment.

Reis (2015) analyzed the process of transition of young people from unemployment to their first job. The results showed that young people with no experience in the labor market have a lower probability of leaving unemployment, even for individuals in the same age group who have had previous work. In addition, the author found that young people and adults with some prior work experience have a similar probability of transition from unemployment to employment.

The contribution of this paper lies in analyzing not the risk of leaving unemployment, as was the goal of the great majority of mentioned studies, but to investigate what factors increase the chances of an individual remaining in this state for more than a year; i.e., when Brazilians are unemployed, which attributes increase or decrease the chances that these people will remain in this state for long periods. 


\section{Data Source and Treatment}

To carry out this empirical exercise, data from the 2013 PNAD are used. According to that survey, that year Brazil had approximately 201.4 million inhabitants, of which 97.9 million were male. Regarding the labor market, considering people aged 15 or older, 101.5 million formed the labor force, called the economically active population (EAP) (Note 5) and 52.5 million were not economically active.

The database used in this work was extracted considering only individuals aged between 15 and 65 years who were unemployed for a period of up to 60 months (Note 6), during the reference week. To answer the queries proposed, an empirical exercise is conducted through the use of a binary response model, which will indicate what personal attributes increase the chances of a worker spending more than 12 months unemployed in Brazil.

Therefore, the dependent variable is binary, and assumes value 0 if the individual remains unemployed up to 12 months, and 1 if he or she remains between 13 and 60 months in that state. Only individuals who actually took action to find work in the reference week of the survey were considered, since Aguas, Pero, and Ribeiro (2014) argue that unemployed people who do not seek or wish to work are closer to the unemployment state than those still looking for work.

Chart 1 shows the explanatory (Note 7) and dependent variables, as well as their descriptions.

Chart 1. Variables used in the proposed model

\begin{tabular}{|c|c|}
\hline Explanatory Variables & Description \\
\hline \multirow{2}{*}{ Gender } & 0 - Female; \\
\hline & 1 - Male. \\
\hline \multirow{4}{*}{ Age } & Id $1-1$ if between 15 to 25 years of age; 0 , otherwise; \\
\hline & Id $2-1$ if between 26 to 35 years of age; 0 , otherwise; \\
\hline & Id $3-1$ if between de 36 to 45 years of age; 0 , otherwise; \\
\hline & Id $4-1$ if between de 46 to 65 years of age; 0 , otherwise; \\
\hline \multirow{2}{*}{ Household head } & 0 - if the individual is not the head of household; \\
\hline & 1 - if the individual is the head of household; \\
\hline \multirow{2}{*}{ Urban } & $0-$ if the individual lives in a rural area \\
\hline & 1 - if the individual lives in an urban area. \\
\hline \multirow{2}{*}{ Black } & 0 - if the individual does not declare his/her race as black; \\
\hline & 1 - if the individual declares his/her race as black; \\
\hline \multirow{4}{*}{ Formal education level } & E1 - No formal education; \\
\hline & E2 - Complete or incomplete "fundamental" school (through $9^{\text {th }}$ grade); \\
\hline & E3 - Complete or incomplete high school; \\
\hline & E4 - Complete or incomplete higher education. \\
\hline \multirow{5}{*}{ Region } & Northeast -1 if the individual resides in Brazil's Northeast; 0, otherwise; \\
\hline & Northwest -1 if the individual resides in Brazil's Northwest; 0, otherwise; \\
\hline & Center-West -1 if the individual resides in Brazil's Center-West; 0 , otherwise; \\
\hline & South - if the individual resides in Brazil's South; 0, otherwise; \\
\hline & Southeast -1 if the individual resides in Brazil's Southeast; 0, otherwise; \\
\hline Dependent Variable & Description \\
\hline \multirow{2}{*}{ Duration } & 0 - if the individual is unemployed for up to 12 months; \\
\hline & 1 - if the individual is unemployed between 13 and 60 months; \\
\hline
\end{tabular}

Source: Prepared by the authors.

Table 1 provides a descriptive overview of the data used. It is worth noting that since the variables in the model are binary, the averages represent the proportion of individuals who are characterized by the value 1 , for example, $52 \%$ of the individuals in the sample are male (Note 8), 10\% are between 13 and 60 months unemployed, $41 \%$ are the heads of household, $89 \%$ live in urban areas and $10 \%$ consider themselves to be black.

Regarding the level of formal education, $5 \%$ of individuals were illiterate, $34 \%$ had an incomplete or complete fundamental education level, $44 \%$ had an incomplete or complete high school level, and $17 \%$ had higher education in progress or complete. Last, considering the age of individuals, 37\% of them were between 15 and 25 years of age, $31 \%$ were between 26 and 35, $19 \%$ were between 36 and 45, and last, $13 \%$ were between 46 and 65 years of age. 
Table 1. Descriptive statistics of the variables used

\begin{tabular}{cccccc}
\hline Variables & Observations & Mean & Standard-Deviation & Minimum & Maximum \\
\hline Duration & 7674 & 0.10 & 0.29 & 0 & 1 \\
Household H. & 7674 & 0.41 & 0.49 & 0 & 1 \\
E1 & 7674 & 0.05 & 0.22 & 0 & 1 \\
E2 & 7674 & 0.34 & 0.47 & 0 & 1 \\
E3 & 7674 & 0.44 & 0.49 & 0 & 1 \\
E4 & 7674 & 0.17 & 0.37 & 0 & 1 \\
Urban & 7674 & 0.89 & 0.31 & 0 & 1 \\
Black & 7674 & 0.10 & 0.49 & 0 & 1 \\
Gender & 7674 & 0.52 & 0.49 & 0 & 1 \\
Id1 & 7674 & 0.37 & 0.48 & 0 & 1 \\
Id2 & 7674 & 0.31 & 0.46 & 0 & 1 \\
Id3 & 7674 & 0.19 & 0.39 & 0 & 1 \\
Id4 & 7674 & 0.13 & 0.34 & 0 & 1 \\
Northeast & 7674 & 0.32 & 0.34 & 0 & 1 \\
Northwest & 7674 & 0.13 & 0.33 & 0 & 1 \\
Center-West & 7674 & 0.12 & 0.14 & 0 & 1 \\
South & 7674 & 0.15 & 0.45 & 0 & 1 \\
Southeast & 7674 & 0.28 & & 1 \\
\hline
\end{tabular}

Source: Prepared by the authors.

\subsection{Long-Term Unemployment Profile in Brazil}

After presenting and describing the data, it is pertinent to conduct a descriptive analysis of long-term unemployment behavior in Brazil, with the aim of finding some evidence of its determinants. Figure 1 below presents the evolution of the annual average unemployment over the past decade in Brazil. The data show that between 2001 and 2013, on average 13\% of the unemployed were in that condition for between 13 and 60 months. In general, the proportion of unemployed people showed average reduction of $3.9 \%$ per annum between 2001 and 2013.

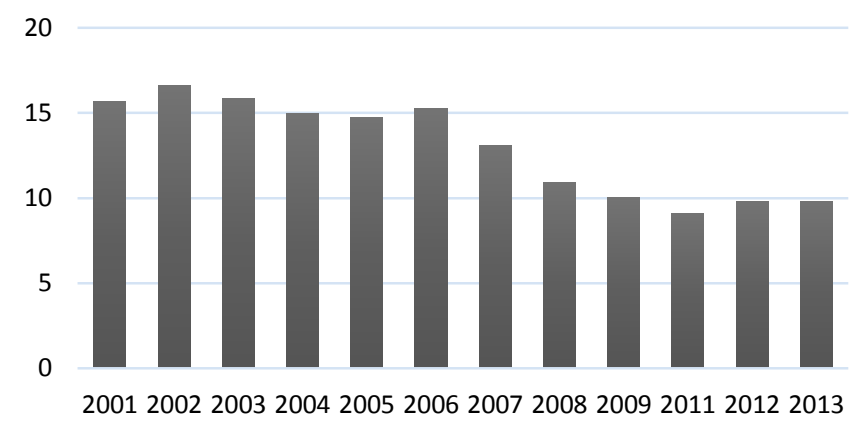

Figure 1. Proportion of Individuals who have been unemployed between 13 and 60 months in Brazil (\%) Source: Prepared by the authors using data from the PNAD survey

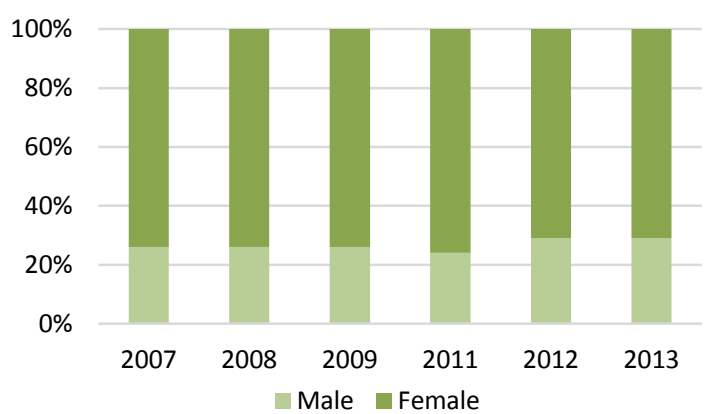

Figure 2. Proportion of Unemployed in Brazil for 13 to 60 months by gender

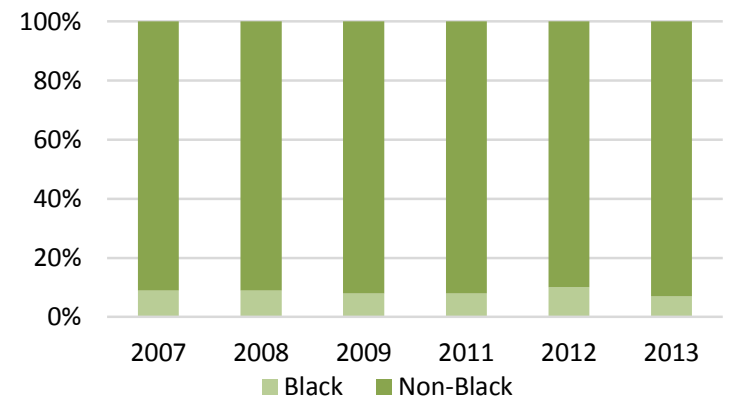

Figure 3. Proportion of Unemployed in Brazil for 13 to 60 months by race

Source: Prepared by the authors using data from the PNAD survey. Source: Prepared by the authors using data from the PNAD survey. 


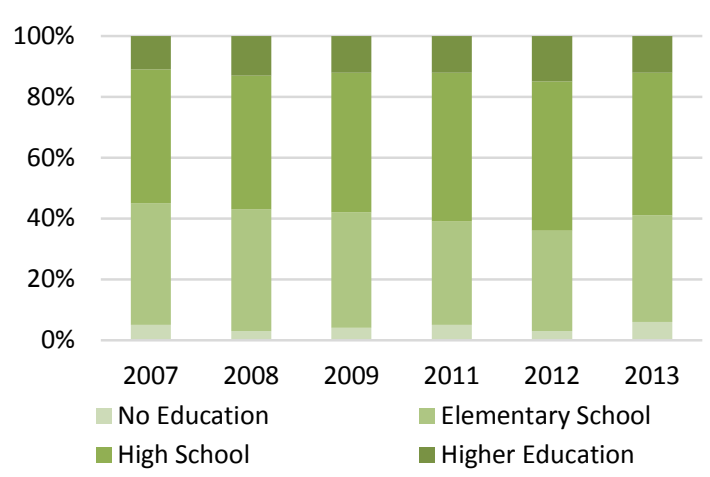

Figure 4. Proportion of Unemployed in Brazil for 13 to 60 months by education

Source: Prepared by the authors using data from the PNAD survey.

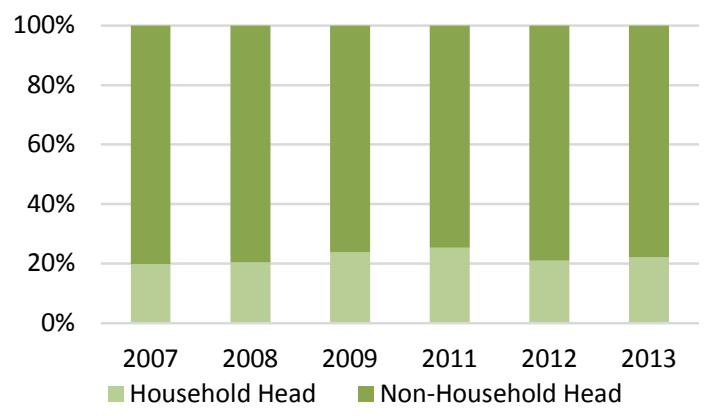

Figure 6. Proportion of Unemployed in Brazil for 13 to 60 months by household position

Source: Prepared by the authors using data from the PNAD survey.

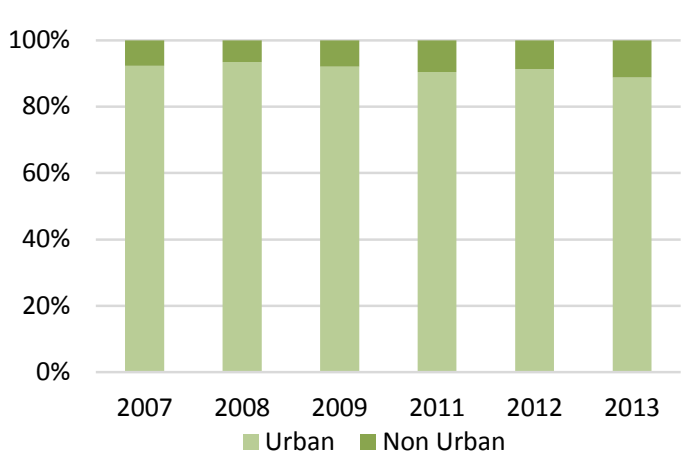

Figure 5. Proportion of Unemployed in Brazil for 13 to 60 months by area

Source: Prepared by the authors using data from the PNAD survey.

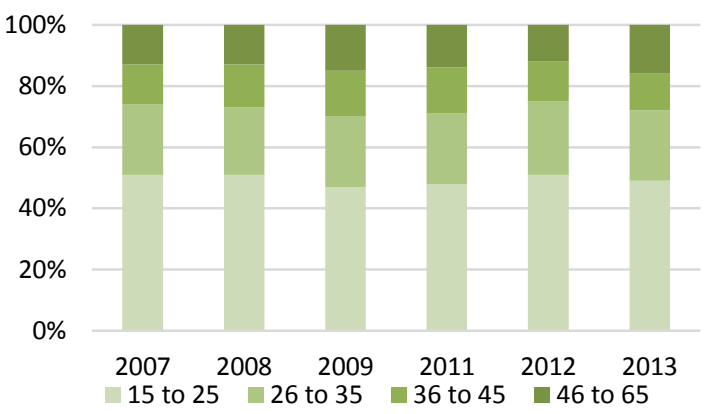

Figure 7. Proportion of Unemployed in Brazil for 13 to 60 months by age

Source: Prepared by the authors using data from the PNAD survey.

An analysis was then performed of the evolution of the distribution of this indicator for each explanatory variable in the model, between 2007 and 2013. The sample used to build the graphs above includes only individuals who are unemployed for more than one year and are still looking for a job. In general, as can be seen in graphs 2-7, there are no significant changes in the characteristics of individuals unemployed from 2007 to 2013 , i.e. there are no major changes in the profiles of the unemployed in the period.

Figure 2 shows a comparison between the proportion of men and women who are in a condition of long-term unemployment, and shows that the proportion of men in this state varies between $24 \%$ and $29 \%$, and for women, from $71 \%$ to $76 \%$ in the period analyzed. Observing the other charts, it can be surmised that, on average, the largest share of individuals who are unemployed for a period of 13 to 60 months are female (73\%), non-black (92\%), young people between 15 and 25 years (50\%), living in urban areas $(91 \%)$, not the head of household (78\%), and with incomplete or complete high school (47\%).

Due to the disparities between Brazil's regions, this work also undertakes an analysis of the regional differences in long-term unemployment. Figure 8 shows the percentage of individuals unemployed for over a year by region.

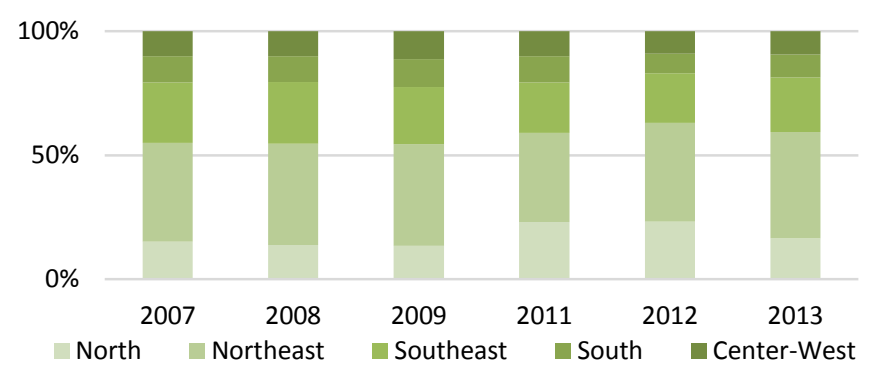

Figure 8. Proportion of unemployed between 13 and 60 months in Brazil by region

Source: Prepared by the authors using data from the PNAD survey. 
As in the other previous charts, no considerable variation in the percentage of individuals who have been unemployed for over 12 months is observed. Hence, there is a certain constancy in this distribution among the regions of Brazil. On average, it turns out that the largest share of the unemployed is in the Northeast region of the country $(40 \%)$. As for the regions with the lowest average proportion of individuals in this condition, they are the Midwest and South (10\%).

Considering the results shown in Figure 8, it is clear that the regional factor must be considered in any research concerning unemployment. Thus, when performing a regional analysis, one can expect to obtain more accurate estimates in order to draw a profile of people who are unemployed for more than one year, and provide evidence that can contribute to the formulation of policies to mitigate regional disparities in the country.

\section{The Binary Response Model}

The binary response model is formulated using the concept of a unobserved variable (called the latent variable), which is assumed to have a determined probability distribution (Davidson \& MacKinnon, 2004). Accordingly, the model specification with the observed dependent binary variable is given by:

$$
Y_{i}=X_{i}^{\prime} \beta+\mu_{i}
$$

Where $Y_{i}=1$ if success occurs, or $Y_{i}=0$, otherwise. As the estimation of this model does not guarantee that $Y_{i}$ will be contained in the $(0,1)$ interval, it is reformulated through the creation of a latent variable $\left(Y_{i}^{0}\right)$ to replace $Y_{i}$. The sign of the unobserved latent variable, $Y_{i}^{0}$, will determine the value that the observed binary variable, $Y_{i}$, will assume; i.e., if $Y_{i}^{0}$ is positive or negative, $Y_{i}$ assumes value 1 or 0 , respectively. Thus, it is possible to compute the probability that $Y_{i}$ will assume value 1 , which is given by:

$$
\begin{gathered}
\operatorname{Pr}\left(Y_{i}=1\right)=\operatorname{Pr}\left(Y_{i}^{0}>0\right)=\operatorname{Pr}\left(X_{i}^{\prime} \beta+u_{i}>0\right)=\operatorname{Pr}\left(u_{i}>-X_{i}^{\prime} \beta\right) \\
=\operatorname{Pr}\left(u_{i}<X_{i}^{\prime} \beta\right)=\Phi\left(X_{i}^{\prime} \beta\right)
\end{gathered}
$$

where $\Phi\left(X_{i}^{\prime} \beta\right)$ is the cumulative distribution of a symmetric probability function.

Different assumptions about $\Phi$ will give rise to different binary response models. For instance, if $\Phi$ is the cumulative distribution of a standard normal variable, the model is called probit. If $\Phi$ refers to the logistic distribution, the model is logit, and so on. Obviously, a class of asymmetric distributions may be used as well, such as the Gompertz distribution, which gives rise to the gompit model.

To choose among different models requires specification tests. However, as we are dealing with a typical case of a symmetric distribution, the choice for the probit model can be justified. The probit and the logit models are the most common ones to represent symmetric distribution problems. They are also practically indistinguishable (Train, 2003), the only difference being that the logistic distribution has slightly fatter tails than the normal distribution. In this particular case, there is no reason to assume that the empirical distribution of the data would produce a distribution with fatter tails than the normal. Because of that, the probit model was adopted.

In this work the observed variable assumes the value of 1 if in the 2013 PNAD survey reference week, the individual has been unemployed between 13 and 60 months; if such an individual is unemployed for less than 13 months, this variable assumes the value of 0 .

In this model, the marginal effects of the regressors on the probabilities will not be given directly by the coefficients of the explanatory variables. Thus for $\operatorname{Prob}\left(y_{i}=1\right)$, the marginal effects of changes in the explanatory variables are given by:

$$
\frac{\partial \operatorname{Prob}(y=1)}{\partial x}=\phi\left(x^{\prime} \beta\right) \cdot \beta
$$

where $\phi\left(x^{\prime} \beta\right)$ is the density function of a standard normal variable.

It can be observed above that when the value of one of the regressors is augmented, $\operatorname{Prob}\left(y_{i}=1\right)$ will increase if the sign of the coefficient of the augmented variable is positive, and will decrease if the coefficient is negative.

\section{Analysis and Discussion of the Results}

To investigate the determinants of long-term unemployment in Brazil, a probit model was estimated. Initially, the existence of heteroscedasticity was tested, using the White and Breusch- Pagan / Cook-Weisberg procedures, and both tests indicated that the error variance, as expected, is not constant, so we chose the option of robust standard errors in the presence of heteroscedasticity. Furthermore, the model was shown to be significant overall, both through the Wald statistic as well as the likelihood ratio; that is, one can reject the hypothesis that all coefficients are zero, at the $1 \%$ significance level. The results of these tests are reported in Table 2.

In general terms, the variables are statistically significant at the usual levels, with the exception of variables 
Urban, Idl and CO. Therefore, living in urban areas does not seem to influence the probability of remaining out of work when compared to living in the countryside; being aged between 15 and 25 does not seem to reduce the chances of spending more than a year unemployed, compared to those with between 46 and 65 years of age, and, also there is no robust evidence of the impact of residing in the Center-West region on the chances of remaining jobless for more than a year.

If an unemployed worker is the head of the family or household, the probability that this individual will remain unemployed for more than 12 months is lower, as indicated by the sign of the coefficient of the Household variable, which is significant at $1 \%$. This result was also found by Menezes Filho and Picchetti (2000) and Avelino (2001).

The dummy variables for the age indicate that the younger the unemployed person is, the lesser is the chance that he or she will remain unemployed for over a year, as was also observed by Penido and Machado (2002) and Oliveira and Carvalho (2006).

Furthermore, the model shows that the lower the educational level of the worker is, the greater is the probability of remaining out of work for more than one year. Similar results were also found by Menezes Filho and Picchetti (2000) and Penido and Machado (2002).

For male workers, the chances of spending more than 12 months unemployed are also lower, indicating some gender discrimination in the Brazilian labor market. Authors such as Avelino (2001), and Menezes and Dedeca (2006), and Reis (2015) also have reported similar results.

The unemployed who identified themselves as black are less likely to remain unemployed for more than a year, a result that confirms the findings of Reis and Aguas (2014), presenting evidence that black people are more likely to leave unemployment for formal and informal jobs than whites. Since this work focuses on explaining the chances of persisting for more than 12 months in unemployment, this result indicates that individuals who identify themselves as black have a lower reservation wage than others, and therefore are less selective in the job search. Pereira et al. (2006), studying reservation wages for the Brazilian Northeast, found similar results. Ogunro (2009) suggested that black people may have lower reservation wages because these individuals have faced discrimination in the job market and have adapted their expectations according to the lower offers of discriminatory employers.

Lastly, the analysis of the chances of remaining unemployed for more than one year in a regional perspective, using the Southeast as a reference, shows that individuals who reside in the Northeast and North are more likely to spend more than 12 months unemployed, and those living in the South have lower chances of remaining in this state. Therefore, the results suggest that the most dynamic labor market in Brazil is in the South.

As previously reported, the estimated coefficients of the probit model only indicate the overall direction of the impact that the explanatory variable of the respective coefficient, ceteris paribus, causes on the probability of remaining unemployed for over a year. To obtain the magnitudes of such impacts, the marginal effects were estimated from equation 3 . Those effects are also presented in Table 2.

Table 2. Results for the estimated probit model

\begin{tabular}{cccccc}
\hline Variables & Coef. & Marginal Effects & Robust Standard Error & Z Statistic & P Value \\
\hline Gender* & -0.57 & -0.084 & 0.04 & -12.69 & 0.00 \\
Black* & -0.19 & -0.024 & 0.08 & -2.50 & 0.01 \\
Urb** & 0.05 & 0.006 & 0.07 & 0.65 & 0.52 \\
Household* & -0.41 & -0.055 & 0.04 & -8.37 & 0.00 \\
E1* & 0.45 & 0.086 & 0.11 & 4.06 & 0.00 \\
E2* & 0.33 & 0.051 & 0.07 & 4.66 & 0.00 \\
E3* & 0.21 & 0.031 & 0.06 & 3.11 & 0.00 \\
Id1** & -0.08 & -0.011 & 0.06 & -1.21 & 0.22 \\
Id2* & -0.36 & -0.046 & 0.07 & -5.10 & 0.00 \\
Id3* & -0.45 & -0.052 & 0.07 & -5.84 & 0.00 \\
Northwest* & 0.33 & 0.054 & 0.06 & 4.79 & 0.00 \\
Northeast* & 0.30 & 0.047 & 0.05 & 5.49 & 0.00 \\
South* & -0.15 & -0.020 & 0.07 & -1.96 & 0.02 \\
Center-West** & -0.009 & -0.001 & 0.07 & -0.12 & -0.90 \\
\hline \multicolumn{6}{c}{ Wald test } \\
\multicolumn{7}{c}{ Chi2 $(14)=382.19$} & Likelihood Ratio & Chi2(14)=441.73 \\
\hline
\end{tabular}




\begin{tabular}{cccc}
\hline & P-Value $=0.00$ & & P-Value $=0.00$ \\
\hline Observations & 7674 & White Heteroscedasticity & Chi2 $2(93)=574.75$ \\
LogLikelihood & -2195.116 & Test & P-Value $=0.00$ \\
\hline McFadden $\mathrm{R}^{2}$ & 0.09 & Breusch-Pagan/Cook-Weisbe & Chi2 $2(1)=1486.50$ \\
${\text { Count } \mathrm{R}^{2}}$ & 0.91 & rg Heteroscedasticity Test & P-Value $=0.00$ \\
\hline
\end{tabular}

Source: Prepared by the authors based on the results. * Significant at the $5 \%$ level **Not significant at the usual levels.

Table 2 also shows that the marginal effect of the Urban, idl and Center-West variables are statistically insignificant, indicating that when comparing identical individuals, apart from those individuals living in urban areas (compared to those living in rural areas), or having between 15 and 26 years of age (compared to those with between 46 and 65 years of age), or living in the Center-West region of the country (compared to those residing in the Southeast), the probability of remaining unemployed for more than a year does not change. All other marginal effects are statistically robust at the usual levels.

Corroborating what was previously mentioned, the variables Household head, Black, Gender and South, in addition to the age dummy variables $I d 2$ and $I d 3$, negatively influence the probability of an individual remaining out of work for more than a year, while the formal education dummy variables, E2, E3 and E4, and the North and Northeast regions affect this probability in an analogous manner.

Regarding the magnitude of the impact, among the variables with a negative impact, males have an average likelihood 8.4\% lower than females of remaining unemployed for over a year. Individuals aged between 26 and 35 have, on average, a chance about $4.6 \%$ less than those aged between 46 and 65 years of age of remaining for more than 12 months unemployed. This chance is $5.2 \%$ lower for individuals aged between 36 and 45 years of age.

The individuals who are the head of a household are, on average, 5.5\% less likely to stay unemployed for over a year compared to those who are not. Those who identify themselves as black, on average, have a chance to remain unemployed for over 12 months $2.4 \%$ lower than those who say they are not black. Lastly, unemployed workers who live in the South region are on average $2 \%$ less likely to be in this state for more than a year, compared to those who live in the Southeast.

Likewise, comparing the variables with a positive impact, individuals without formal education have, on average, an $8.6 \%$ greater chance than those with a college education or studying at a college of staying unemployed for more than 12 . This chance is $5.1 \%$ and $3.1 \%$ higher, respectively, for individuals with incomplete or complete fundamental school and for individuals with high school education or who are currently going to high school. Lastly, unemployed workers who are in the North and Northeast regions have respectively a $5.4 \%$ and $4.7 \%$ higher chance of remaining in this state for more than a year compared to those who live in the Southeast.

In order to clarify the role of the estimated probabilities, we calculated probabilistic scenarios (Note 9) for the model. With the construction of these scenarios, apart from attesting to the effects that changes in the explanatory variables cause on the probability of remaining unemployed, one can measure the likelihood that an individual with certain characteristics will remain unemployed.

These scenarios reveal, for example, that an individual living in the Northeast region, who is a male, illiterate, aged between 15 and 25 years of age and not the head of household, has a $17 \%$ chance of remaining unemployed for over 12 months; while a female with the same features has a probability of $35 \%$. Under the same conditions, if the person is living in the South or Southeast regions, the probability of spending more than a year unemployed is $10 \%$. In general terms, the other results show that for any given change in the characteristics of individuals, women have higher chances of spending more than a year unemployed, and also those living in the South and Southeast regions have the lowest probabilities of staying unemployed for over 12 months.

The unemployed aged between 36 and 45 years of age have the lowest odds of remaining unemployed for over 12 months, among all age groups analyzed. Similarly, individuals with less formal instruction are more likely to remain unemployed for more than a year, compared to those with higher levels of education in all cases considered. In conclusion, those least likely to remain jobless for more than 12 months are males, between 36 and 45 years of age, resident in the South or Southeast, heads household, and with higher level of education, with only a $0.6 \%$ chance, while the greatest chance of remaining jobless is among women, between 46 and 65 years of age, illiterate and not the head of a household, with a $41 \%$.

\section{Concluding Remarks}

This work analyzed the determinants of the probabilities of remaining unemployed for more than a year in Brazil, 
using micro data from the 2013 National Household Survey (PNAD), and a dichotomous model based on a normal distribution.

The probabilities of remaining unemployed for more than one year are lower for Brazilians aged between 36 and 45 years. The analysis of the marginal effects also showed that individuals belonging to this age group have, on average, a probability 5.2\% lower when compared to older individuals of remaining unemployed. Under the same conditions, individuals between 26 and 35 years of age have on average have a probability of remaining unemployed that is $4.6 \%$ lower than that of the individuals between 46 and 65 years of age.

Individuals with a higher level of education have lower chances of staying unemployed for over 12 months, which corroborates the results found by Menezes Filho and Picchetti (2000) and Penido and Machado (2002), among others. The marginal effects also reveal that the Brazilian illiterate people have on average an $8.6 \%$ greater chance of spending more than a year unemployed than that of individuals with higher education This chance is $5.1 \%$ and $3.1 \%$ greater, respectively, for individuals with fundamental and high school, either having completed that level of education or being currently in school.

Individuals who claim to be black are less likely to remain unemployed for over a year. The marginal effects show that the fact of being black provides a chance on average 2.4\% lower than those who report not being black. Evidence in this direction was also obtained by Reis and Aguas (2014). When it comes to long-term unemployment, the evidence suggests that black people have a lower reservation wage, so they are willing to accept a wider variety of possible jobs. This result, however, needs to be examined more cautiously, since it is necessary to investigate the kind of work and remuneration received by these individuals.

The results also indicate gender discrimination in the Brazilian labor market, as found by Avelino (2001) and Oliveira and Carvalho (2006), among others. The marginal effect shows that a male individual has, on average, an $8.4 \%$ lower probability than that of an individual who is female of remaining unemployed for over a year. The model also confirmed that heads of household have lower chances of staying unemployed for over a year, a result also found in other studies, such as Menezes Filho and Picchetti (2000) and Avelino (2001).

The analysis of the probabilistic scenarios revealed that Brazilian individuals who are least likely to remain unemployed for more than a year are males, resident in the South or Southeast, head of a household, or main income provider of a family, between 36 and 45 years of age, with a higher level of education, with only a $0.6 \%$ chance of remaining unemployed. On the other hand, individuals with the highest chance of long-term unemployment are females, between 46 and 65 years old, illiterate and not head of a household, with a $41 \%$ probability.

In short, these results suggest that public policies for job creation should give priority to education, particularly to reduce the number of illiterates; recycling of older people in professional terms, and incentives for a greater participation and inclusion of women in the labor market.

\section{Acknowledgements}

The authors would like to thank the Conselho Nacional de Desenvolvimento Científico e Tecnológico (CNPq) for funding this research.

\section{References}

Aguas, M. F. F., Pero, V. L., \& Ribeiro, E. P. (2014). Heterogeneity in the Labor Market: Unemployment and Non-Participation in Brazil. Economia Aplicada, 18(3), 355-378. https://doi.org/10.1590/1413-8050/ea471

Alogoskoufis, G. S., Maning, A., Calmfors, L., \& Danthine, J. P. (1988). On the Persistence of Unemployment. Economic Policy, 3(7), 427-469. https://doi.org/10.2307/1344492

Antigo, M. F., \& Machado, A. F. (2006). Transições e duração do desemprego: Uma revisão da literatura com novas evidências para Belo Horizonte. Nova Economia, 16(3), 375-406. https://doi.org/10.1590/S0103-63512006000300001

Atkinson, T. (1998). Social Exclusion, Poverty and Unemployment. In A. B. Atkinson, \& J. Hills (Eds.), Exclusion, Unemployment and Opportunity. CASEPaper. CASE/4. Centre for Analysis of Social Exclusion. London School of Economics.

Avelino, R. R. G. (2001). Os Determinantes da Duração de Desemprego em São Paulo. Texto para Discussão, no 11, São Paulo: USP/IPE.

Barro, R. (1988). The Persistence of Unemployment. The American Economic Review, 78(2), 32-37.

Baumann, R. (2001). Brazil in the 1990s: An Economy in Transition. Cepal Review, 73, 147-169. 
Beleva, I. (1997). Long-Term Unemployment as Social Exclusion. In N. Genov (Ed.), Bulgaria. Human Development Rerport (pp. 29-36).

Bivar, W. (1993). Estimativas da duração média do desemprego no Brasil. Pesquisa e Planejamento Econômico, 23(2), 275-312.

Boršič, D., \& Kavkler, A. (2009). Modeling unemployment duration in Slovenia using Cox regression models. Transition Studies Review, 16, 145-156. https://doi.org/10.1007/s11300-009-0053-6

Davidson, R., \& Mackinnon, J. G. (2004). Econometric Theory and Methods. New York: Oxford University Press.

Ehrenberg, R. G., \& Smith, R. S. T. (2008). Modern Labor Economics: Theory and Public Policy. International Edition. Pearson Education.

Heintz, J., \& Vanek, J. (2007). Employment, the Informal Sector, and Poverty: Data and Analytical Challenges. Research Design Conference, Cambridge Massachusetts.

La Porta, R., \& Shleifer, A. (2014). Informality and Development. Journal of Economic Perspectives, 28(3), 109-126. https://doi.org/10.1257/jep.28.3.109

Lancaster, T. (1979). Econometric methods for the duration of unemployment. Econometrica, 47(4), 939-956. https://doi.org/10.2307/1914140

Lancaster, T., \& Nickel, S. (1980). The analysis of reemployment probabilities for the unemployment. Journal of the Royal Statistical Society, 143(2), 141-165. https://doi.org/10.2307/2981986

Menezes, W. F., \& Dedeca, C. S. (2006). Avaliação da duração do desemprego nas regiões metropolitanas de Salvador e de São Paulo. Revista de Economia Contemporânea, 10(1), 35-60. https://doi.org/10.1590/S1415-98482006000100002

Meneses, A. I., \& Cunha, M. S. (2012). Evidências sobre a duração do desemprego no Brasil no período recente. In: XV Encontro da ANPEC-SUL, 2012, Porto Alegre. XV Encontro da ANPEC-SUL.

Menezes-Filho, N. A., \& Picchetti, P. (2000). Os determinantes da duração do desemprego em São Paulo. Pesquisa e Planejamento Econômico, 30(1), 23-48.

Nickel, S. (1979). Estimating the probability of leaving unemployment. Econometrica, 47(4). https://doi.org/10.2307/1911961

Oliveira, V. H., \& Carvalho, J. R. (2006). Os Determinantes da Duração do Desemprego no Brasil: Uma Análise com Dados da Pesquisa de Padrão de Vida do IBGE. In: XI Encontro Regional de Economia, Fortaleza. Anais do XI Encontro Regional de Economia. Fortaleza: Banco do Nordeste.

Ogunro, N. (2009). Three Essays on the Black White Wage Gap. Knowledge, Dissertation. University of Kentucy.

Penido, M., \& Machado, A. F. (2000). Duração de desemprego na região Metropolitana de Belo Horizonte. In: X Seminário sobre Economia Mineira, Belo Horizonte - MG, 2000.

Penido, M., \& Machado, A. F. (2002). Desemprego: Evidências da Duração no Brasil Metropolitano. Texto para discussão, 176, Belo Horizonte: UFMG/Cedeplar.

Pereira, M. L., Monte, P. A., \& Ramalho, H. M. B. (2009). Uma estimação do salário de reserva para a região Nordeste e o Brasil em 2006. In Fórum do XIV Encontro Regional de Economia do Nordeste - ANPEC Regional, 2009, Fortaleza. XIV Encontro Regional de Economia do Nordeste.

Reis, M. (2015). Uma análise da transição dos jovens para o primeiro emprego no Brasil. Revista Brasileira de Economia, 69(1), 125-143. https://doi.org/10.5935/0034-7140.20150006

Reis, M., \& Aguas, M. (2014). Duração do desemprego e transições para o emprego formal, a inatividade e a informalidade. Economia Aplicada, 18(1), 35-50. https://doi.org/10.1590/1413-8050/ea416

Schneider, J. A. (2011). Who are the Long Term Unemployed in this Recession and What can be done to Help Them? Policy Report. George Washington University.

Theodossiou, I., \& Zarotiadis, G. (2010). Employment and unemployment duration in less developed regions. Journal of Economic Studies, 37(5), 505-524. https://doi.org/10.1108/01443581011075442

Train, K. (2003). Discrete Choice Methods with Simulation. Cambridge University Press. https://doi.org/10.1017/CBO9780511753930 


\section{Notes}

Note 1. For more information on the changes the Brazilian economy underwent in that period, see the discussions in Baumann (2001).

Note 2. See Atkinson (1998) and Beleva (1997).

Note 3. For a detailed analysis on the relationship between the informal sector and poverty, see La Porta and Shleifer (2014) and Heintz and Vanek (2007).

Note 4. In this work, long-term unemployment is defined as the situation in which the individual is unemployed between 13 and 60 months and took action to seek employment in the reference week of the survey.

Note 5. The EAP consists of the employed and unemployed populations. People outside the labor force are classified as not economically active (or inactive).

Note 6. Individuals out of work for over 60 months can be classified as discouraged, where people no longer actively seek work since they do not believe they will find it.

Note 7. The choice of these variables is based on Bivar (1993), Menezes Filho and Picchetti (2000), Penido and Machado (2002), Oliveira and Carvalho (2006) and Ehrenberg and Smith (2008).

Note 8 . The binary variables such as male and black are complementary to female, and non-black; Thus, the proportions of female and non-black people are $48 \%$ and $90 \%$ of the sample, respectively.

Note 9 . The tables with the probabilistic scenarios can be obtained by contacting any of the authors.

\section{Copyrights}

Copyright for this article is retained by the author(s), with first publication rights granted to the journal.

This is an open-access article distributed under the terms and conditions of the Creative Commons Attribution license (http://creativecommons.org/licenses/by/4.0/). 